\title{
Methadone Treatment Induces Attenuation of Cerebrovascular Deficits Associated with the Prolonged Abuse of Cocaine and Heroin
}

\author{
Ronald I Herning*,', Warren E Better', Kimberly Tate', Annie Umbricht ${ }^{2}$, Kenzie L Preston ${ }^{2}$ and Jean L \\ Cadet' \\ 'Molecular Neuropsychiatry Section, National Institute on Drug Abuse, National Institutes of Health, Baltimore, MD, USA; ${ }^{2}$ Treatment Section, \\ National Institute on Drug Abuse, National Institutes of Health, Baltimore, MD, USA
}

\begin{abstract}
Opiate replacement therapy has been useful in reducing heroin use and in keeping patients in treatment programs. However, neuropsychological and neurophysiological effects of this treatment regimen have not been evaluated systematically. To determine whether methadone treatment reduces the magnitude of cerebral blood flow alternations in polysubstance (heroin and cocaine) abusers, we compared blood flow parameters in control subjects $(n=26)$, polysubstance abusers $(n=28)$ maintained on methadone for 24 weeks, and polysubstance abusers $(n=22)$ who were not seeking treatment. Blood flow velocity was recorded from the anterior and middle cerebral arteries using transcranial Doppler sonography on an outpatient visit. The pulsatility index, a measure of cerebrovascular resistance, was significantly $(p<0.05)$ increased in both groups of polysubstance abusers compared to control subjects. Increased pulsatility in the two groups of substance abusers suggests constriction of the small cortical arteries. Nevertheless, the methadonemaintained polysubstance abusers had significantly lower pulsatility values than the nontreatment substance-abusing group. These findings suggest that maintenance on methadone might have significant beneficial neurovascular effects on this population of patients. Neuropsychopharmacology (2003) 28, 562-568. doi:I 0.1038/sj.npp. 1300073
\end{abstract}

Keywords: heroin; cocaine; methadone; cerebral perfusion; cerebrovascular resistance; polysubstance abuse

\section{INTRODUCTION}

Nearly a million people in the United States regularly abuse heroin (Community Epidemiology Work Group, 2001). The use of heroin among high school seniors in the United States has also increased (Monitoring the Future Study, 2000). Many heroin-dependent individuals also abuse cocaine, marijuana, and alcohol (Hser et al, 2001). These substance abusers are at risk for many medical problems, including collapsed veins, endocarditis, abscesses, cellulitis, hepatitis, pneumonia, lymphadenopathy, spongiform leukoencephalopathy, and HIV/AIDS (Ben Diane et al, 2000; Hser et al, 2001). Treatment approaches such as methadone, $1-\alpha$ acetomethadol, and buprenorphine, which are useful in reducing heroin use and in keeping patients in treatment

\footnotetext{
*Correspondence: Dr RI Herning, Molecular Neuropsychiatry Section, National Institute on Drug Abuse/IRP, 5500 Nathan Shock Drive, Baltimore, MD 21224, USA, Tel: +1 410 550-155I, E-mail: rherning@intra.nida.nih.gov

Received 24 February 2002; revised II September 2002; accepted 16 September 2002

Online publication: 25 September 2002 at http://www.acnp.org/ citations/Npp0925002392
}

programs (O'Connor and Fiellin, 2000; Johnson et al, 2000), might reduce health risks in these patients.

In addition to the acute medical problems listed above, areas of reduced cortical perfusion have been reported in heroin-dependent individuals during early abstinence (Levin et al, 1995; Rose et al, 1996; Danos et al, 1998). Specifically, SPECT scans performed after a clonidinesupported 5-day detoxification schedule revealed reduced perfusion in the frontal, temporal, parietal cortices (Rose $e t$ $a l, 1996)$. The perfusion deficits in these areas were reported to improve after 2 weeks of abstinence (Rose et al, 1996). Levin et al (1995) also reported that areas of reduced cortical perfusion observed in SPECT scans of polysubstance (heroin and cocaine) abusers improved after several weeks of treatment with buprenorphine. Interestingly, Danos et al (1998) found that blood flow, measured by SPECT, in the parietal cortex was correlated with the dose of methadone that heroin-dependent patients were receiving, with methadone causing a substantive increase in perfusion. Further support for the notion that reduced perfusion in heroin-dependent individuals is related to opiate withdrawal comes from a SPECT study of regional cerebral blood flow in humans during naltrexone-precipitated withdrawal from buprenorphine (van Dyck et al, 
1994). In this study, the severity of the precipitated withdrawal was correlated with a reduction of blood flow in the anterior cingulate cortex. Individuals who abuse both heroin and cocaine might also show reductions in cerebral perfusion secondary to their prolonged use of cocaine. For example, several investigators using position emission tomography (PET) and SPECT (Tumeh et al, 1990; Weber et al, 1990; Volkow et al, 1991; Holman et al, 1991; Levin et al, 1994, 1995) as well as transcranial Doppler sonography (TCD) (Herning et al, 1999) have reported reduced perfusion in cocaine abusers. Thus, cocaine and heroin may potentiate each other's influence on cerebral blood flow.

It is thus important to relate this discussion to the possible beneficial effects of opiate replacement therapy, which include reduced craving for heroin, reduced needs for drug-seeking behaviors, as well as reduced relapse rates (O'Connor and Fielin, 2000; Johnson et al, 2000). While these treatment approaches would substantially reduce infection rates in that population, the effects of long-term opiate replacement therapy on cerebral blood flow have not been reported. Yet, it is important to know if opiate replacement therapy has positive, negative, or no effects on cerebral blood flow since heroin addicts are often on replacement therapy for extended periods. These issues are of clinical relevance because, if maintenance treatments were to cause additional damage in the brains of these patients, these patients would be at risk for further neuropsychiatric complications. On the other hand, improvement in flow would help to substantiate the need for enlarging the pool of treated patients.

To quantify cerebral blood flow in polysubstance (heroin and cocaine) abusers and to determine how prolonged methadone treatment might influence these changes, we used TCD to compare various indices of blood flow obtained in control subjects to that of polysubstance abusers maintained on methadone for 24 weeks and of polysubstance abusers not seeking treatment. We were thus able to evaluate the effects of methadone when the polysubstance abusers were no longer experiencing the effects of withdrawal during early abstinence.

TCD has proven to be useful in evaluating abnormal hemodynamics in cerebral arteries (Martin et al, 1994; Silvestrini et al, 1996; Howard et al, 1996). An important difference between TCD and other methodologies such as PET or SPECT is that TCD measures blood flow velocity in large arteries rather than cerebral perfusion in small vessels. Pulsatility, an index of vascular resistance, can be obtained from the velocity measures (Arnolds and von Reutern, 1986; Czosnyka et al, 1996; Cho et al, 1997). Changes in blood flow velocity in large arteries imply constriction, partial obstruction or dilation of these vessels (Martin et al, 1994). In addition, changes in cerebral resistance of small cortical blood vessels or pulsatility can be inferred from blood velocity values recorded on large arteries (Cho et al, 1997). Blood pressure must be similar or controlled statistically in the comparison groups for these interpretations of velocity and pulsatility to hold. Since the TCD assessment is noninvasive, economical, and rapid, TCD allows for repeated assessments of large samples of subjects, something that is not usually possible with the PET/SPECT imaging studies.

\section{METHODS}

\section{Subjects}

A total of 28 polysubstance abusers maintained on methadone (Poly/Meth), 22 nontreatment seeking polysubstance abusers (Poly/NTS), and 26 control (CTL) subjects were studied. The methadone-maintained polysubstance abusers were receiving $60-80 \mathrm{mg}$ of methadone per day for $24.3+3.3$ weeks as part of an outpatient treatment study at the Archway Clinic of the NIDA-Intramural Research Program (Preston et al, 2000). The nontreatment seeking polysubstance abusers were screened to determine whether they wanted treatment before entering this study. Before undergoing blood flow velocity assessment by TCD, all volunteers had undergone medical, neurological, psychological, and laboratory evaluations. All the polysubstance abusers met the DSM-IIIR criteria for both heroin and cocaine dependence/abuse using the Diagnostic Interview Schedule (DIS: Robins et al, 1988). Demographic information and drug use history information were obtained from the Addiction Severity Index (ASI: McLellan et al, 1986). Demographic information for the three groups is listed in Table 1.

Exclusion criteria that applied to all subjects include: (1) major medical and psychiatric illnesses, (2) head injuries with loss of consciousness for greater than $5 \mathrm{~min}$, (3) evidence of any neurological abnormalities by history or examination, (4) HIV seropositivity. The research protocol was approved by the National Institute on Drug Abuse and Johns Hopkins Bayview Medical Center Institutional Review Boards for Human Research. Written informed consent was obtained from all subjects. In addition, this research was carried out in accordance with the Declaration of Helsinki of 1975.

\section{Procedures}

Subjects were tested on an outpatient visit. All subjects were assessed for drug use before TCD recording and were required not to smoke tobacco cigarette for $20 \mathrm{~min}$ before TCD recoding. Resting heart rate and blood pressure were also measured in all subjects. The methadone-maintained polysubstance abusers were tested before their daily methadone dose. Blood flow velocity was determined using a temporal window (zygomatic arch) for four arteries: right and left middle (MCA), and right and left anterior (ACA) cerebral arteries using pulsed transcranial Doppler sonography (Nicolet, Model TC2000). A hand-held ultrasound transducer was directed at the cerebral artery of interest using the correct placement on the skull, angle, and depth setting. A shift in sound frequency in the reflected sound is used to calculate the blood flow velocity in that artery. Blood flow velocities from the other cerebral arteries can be obtained by changing transducer location, angle, and depth setting. A mean velocity $\left(V_{\mathrm{m}}: \mathrm{cm} / \mathrm{s}\right)$, systolic velocity $\left(V_{\mathrm{s}}\right.$ : $\mathrm{cm} / \mathrm{s})$, diastolic velocity $\left(V_{\mathrm{d}}: \mathrm{cm} / \mathrm{s}\right)$, and pulsatility index $\left(\mathrm{PI}=\left(V_{\mathrm{s}}-V_{\mathrm{d}}\right) / V_{\mathrm{m}}\right)$ were determined for each artery.

\section{Statistical Analysis}

A group (CTL, Poly/Meth, Poly/NTS) by gender analysis of variance (ANOVA) was used to test for differences in 
Table I Demographic Measures and Drug History

\begin{tabular}{|c|c|c|c|c|c|c|}
\hline & \multicolumn{2}{|l|}{ CTL } & \multicolumn{2}{|l|}{ Poly/Meth } & \multicolumn{2}{|l|}{ Poly/NTS } \\
\hline & Mean & SD & Mean & SD & Mean & SL \\
\hline \multicolumn{7}{|l|}{ Demographic measures } \\
\hline African American (\%) & 80.8 & & 88.2 & & 95.2 & \\
\hline Gender (\% male) & 58.7 & & 60.7 & & 77.8 & \\
\hline Age (years) & 31.1 & 8.5 & $38.8^{*}$ & 8.4 & 34.9 & \\
\hline Education (years) & 13.2 & 1.8 & 11.6 & 1.4 & 11.9 & \\
\hline Weight (pounds) & 161.5 & 29.4 & 156.9 & 33.8 & 168.5 & 37 \\
\hline Monthly income () & 990 & 984 & $1704^{\mathrm{a}}$ & 2335 & $1749^{a}$ & 27 \\
\hline \multicolumn{7}{|l|}{ Type of job } \\
\hline $\begin{array}{l}\text { Laborer: mover, factory worker, } \\
\text { construction, housecleaning, etc }\end{array}$ & Laborer & 4 & Laborer & 8 & Laborer & \\
\hline $\begin{array}{l}\text { Skilled laborer: auto mechanic, } \\
\text { meat cutter, etc }\end{array}$ & Skilled laborer & 4 & Skilled laborer & 6 & Cook & \\
\hline \multirow[t]{5}{*}{ Driver: truck or taxi } & Cook & 3 & Driver & 2 & Clerical work & \\
\hline & Driver & 4 & Clerical work & 4 & Clerk & \\
\hline & Clerical work & 7 & Clerk & 4 & Unemployed & \\
\hline & Clerk & 2 & Unemployed & 3 & Laborer & 10 \\
\hline & Student & 2 & Laborer & 8 & Cook & \\
\hline
\end{tabular}

Drug history measures

Cocaine (days/30)

Cocaine (years)

Heroin (days/30)

Heroin (years)

Alcohol (days/30)

Alcohol (years)

Marijuana (days/30)

Marijuana (years)

Cigarettes/day

Cigarettes (years)

$\begin{array}{rrr} & & 19.3 \\ & & 12.2 \\ & & 28.6 \\ & & 15.7 \\ 1.2 & 2.2 & 5.4 \\ 5.4 & 7.6 & 11.5 \\ & & 1.6 \\ & & 8.2 \\ 4.8 & 8.8 & 13.7 \\ 8.3 & 11.6 & 18.3\end{array}$

\begin{tabular}{rrr}
10.2 & 17.7 & 7.0 \\
9.0 & 9.1 & 6.0 \\
5.7 & 20.2 & 6.7 \\
8.8 & 11.9 & 7.1 \\
7.9 & 8.6 & 9.2 \\
12.9 & 15.2 & 9.7 \\
3.1 & 4.4 & 7.7 \\
10.6 & 8.5 & 8.4 \\
8.8 & 18.8 & 12.5 \\
11.1 & 18.5 & 8.2 \\
\hline
\end{tabular}

*The mean for the Poly/Meth subjects was significantly $(p<0.05)$ higher than that of the CTL subjects using the Bonferroni post hoc procedure. Income includes illegal income.

Table 2 Cardiovascular and Blood Chemistry Measures

\begin{tabular}{|c|c|c|c|c|c|c|}
\hline & \multicolumn{2}{|l|}{ CTL } & \multicolumn{2}{|c|}{ Poly/Meth } & \multicolumn{2}{|c|}{ Poly/NTS } \\
\hline & Mean & SD & Mean & SD & Mean & SD \\
\hline \multicolumn{7}{|l|}{ Cardiovascular } \\
\hline $\begin{array}{l}\text { Heart rate } \\
\text { Systolic blood pressure } \\
\text { Diastolic blood pressure }\end{array}$ & $\begin{array}{r}73.3 \\
124.6 \\
77.9\end{array}$ & $\begin{array}{r}11.1 \\
11.3 \\
9.1\end{array}$ & $\begin{array}{c}71.4 \\
136.8^{*} \\
82.4\end{array}$ & $\begin{array}{l}12.4 \\
16.4 \\
12.8\end{array}$ & $\begin{array}{r}71.6 \\
129.1 \\
77.0\end{array}$ & $\begin{array}{r}12.4 \\
9.8 \\
8.4\end{array}$ \\
\hline \multicolumn{7}{|l|}{ Blood chemistry } \\
\hline $\begin{array}{l}\text { Hematocrit } \\
\text { Hemoglobin } \\
\text { Cholesterol }\end{array}$ & $\begin{array}{r}39.8 \\
13.6 \\
187.2\end{array}$ & $\begin{array}{r}2.8 \\
1.0 \\
45.6\end{array}$ & $\begin{array}{r}40.0 \\
13.6 \\
174.4\end{array}$ & $\begin{array}{r}4.7 \\
1.4 \\
45.5\end{array}$ & $\begin{array}{r}41.7 \\
14.2 \\
173.0\end{array}$ & $\begin{array}{r}4.5 \\
1.5 \\
31.5\end{array}$ \\
\hline
\end{tabular}

*The mean for the Poly/Meth subjects was significantly $(p<0.05)$ higher than that of the other groups using the Bonferroni post hoc procedure.

cardiovascular and blood chemistry measures. A group (CTL, Poly/Meth, Poly/NTS) by gender by side (right $v s$ left) analysis of covariance (ANCOVA) was used to test for differences in flow velocity parameters. Age, systolic, and diastolic blood pressures were covariates in the ANCOVA to control for differences among the groups on these measures (see Tables 1 and 2). Bonferroni multiple comparison post hoc procedure was used to test for differences among means.

\section{RESULTS}

Cardiovascular and blood chemistry values (cholesterol, hematocrit, and hemoglobin) are displayed in Table 2. 
Group differences were only found for systolic blood pressure. No interactions involving gender were significant for any blood flow velocity measures.

\section{Middle Cerebral Artery}

The group main effect for mean velocity for the middle cerebral artery was significant $\left(V_{\mathrm{m}}: \mathrm{F}(2,67)=3.28, p<0.05\right)$ after controlling for age $(\mathrm{F}(1,67)=8.97, p<0.005)$. The other covariates were not significant (systolic blood pressure: $\mathrm{F}(1,67)=3.06, p>0.05$; diastolic blood pressure: $\mathrm{F}(1,67)=0.18, p>0.05)$. The group main effect for $V_{s}$ for the MCA was significant $\left(V_{s}: \mathrm{F}(2,67)=4.93, p<0.01\right)$ after controlling for age $(\mathrm{F}(1,67)=11.11, p<0.001)$. The other covariates were not significant (systolic blood pressure: $\mathrm{F}(1,67)=2.01, p>0.05$; diastolic blood pressure: $F(1,67)=0.80, p>0.05)$. Figure 1 shows the means for systolic velocity averaged over both right and left middle cerebral artery. Mean systolic velocity for the Poly/Meth group is significantly $(p<0.01)$ faster than that of the CTL group using the Bonferroni multiple comparison post hoc procedure. The group main effect for diastolic velocity for the middle cerebral artery was not significant $\left(V_{\mathrm{d}}: \mathrm{F}(2,67)=2.70, \quad p>0.05\right)$ after controlling for age $(\mathrm{F}(1,67)=5.34, \quad p<0.03)$ and systolic blood pressure $(\mathrm{F}(1,67)=4.08, \quad p<0.05)$. Figure 2 shows the means for diastolic velocity averaged over both right and left MCA. The group main effect was significant for PI $(\mathrm{F}(2,69)=9.70, \quad p<0.002)$ after controlling for diastolic blood pressure $(\mathrm{F}(1,67)=4.34, p<0.05)$. Age $(\mathrm{F}(1,67)=$ $3.13, p<0.05)$ and systolic blood pressure $(\mathrm{F}(1,67)=1.72$, $p<0.05)$ were not significant covariates. Figure 3 shows the means PI averaged over both right and left middle cerebral artery. The mean for the Poly/Meth group was significantly $(p<0.02)$ larger than the CTL group and significantly $(p<0.05)$ smaller than the Poly/NTS group (the Bonferroni multiple comparison post hoc procedure). There was no significant group by side interaction for any of the middle cerebral artery measures.

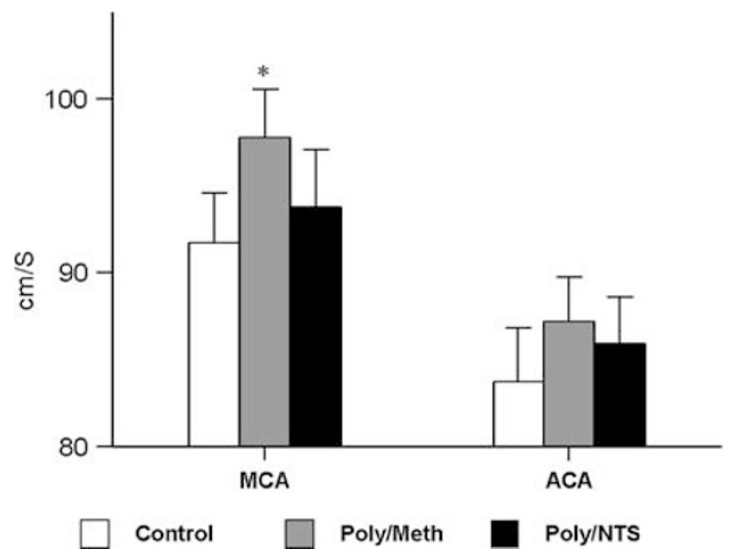

Figure I Group means and standard errors for systolic velocity are plotted for both arteries. The asterisk indicates that the mean for the MCA of the Poly/Meth group is significantly greater than that of the control group $(p<0.0 \mathrm{I})$ using the Bonferroni post hoc procedure.

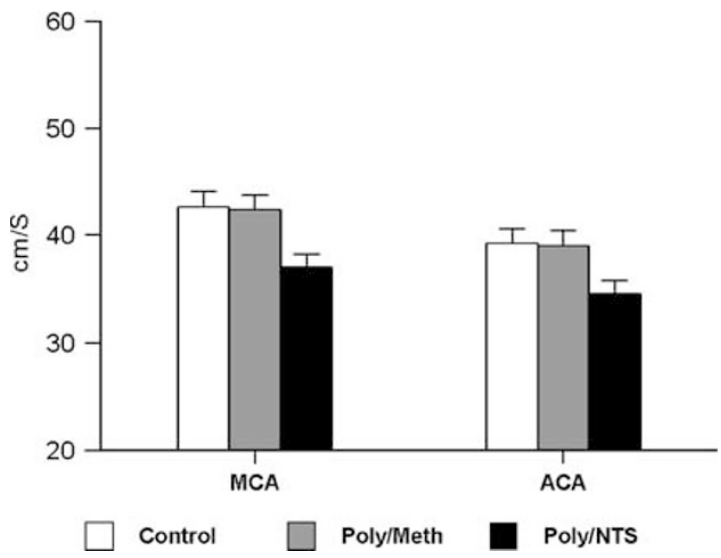

Figure 2 Group means and standard for diastolic velocity are plotted for both arteries. No significant differences were observed among the group for either artery.

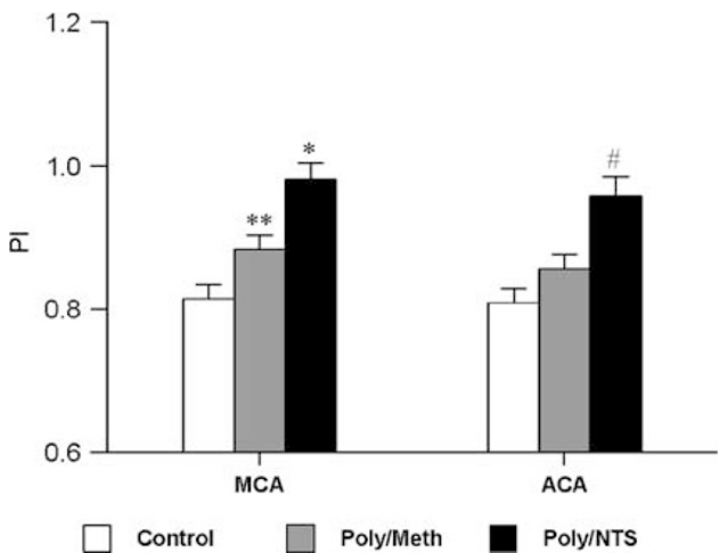

Figure 3 Group means and standard errors for the pulsatility index are plotted for both arteries. The double asterisk indicates that the mean for the MCA of the Poly/Meth group is significantly greater than that of the control group $(p<0.02)$ using the Bonferroni post hoc procedure. The single asterisk indicates that the mean for the MCA of the Poly/NTS group is significantly greater than that of the Poly/Meth group $(p<0.05)$ using the Bonferroni post hoc procedure. The pound sign indicates that the mean for ACA of the Poly/NTS group is significantly greater than the other groups $(p<0.05$ or greater $)$

\section{Anterior Cerebral Artery}

The group main effect for mean velocity for the anterior cerebral was not significant $\left(V_{\mathrm{m}}: \mathrm{F}(2,67)=2.08, p>0.05\right)$ with no significant covariate in the analysis (age: $\mathrm{F}(1,67)=2.42, p>0.05$; systolic blood pressure: $\mathrm{F}(1,67)=$ $0.38, p>0.05$; diastolic blood pressure: $\mathrm{F}(1,67)=0.01$, $p>0.05)$. The group main effect for systolic velocity for the anterior cerebral artery was not significant $\left(V_{s}\right.$ : $\mathrm{F}(2,67)=1.45, p>0.05)$ with no significant covariate in the analysis (age: $\mathrm{F}(1,67)=3.49, p>0.05$; systolic blood pressure: $F(1,67)=0.20, p>0.05$; diastolic blood pressure: $\mathrm{F}(1,67)=0.34, p>0.05)$. Figure 1 shows the means for systolic velocity averaged over both right and left anterior cerebral artery. The group main effect for diastolic velocity for the anterior cerebral artery was not significant $\left(V_{\mathrm{d}}\right.$ : $\mathrm{F}(2,67)=1.55, p>0.05)$ with no significant covariates in the analysis (age: $\mathrm{F}(1,67)=2.66, p>0.05$; systolic blood pressure: $\mathrm{F}(1,67)=1.16, \quad p>0.05$; diastolic blood pressure: 
$\mathrm{F}(1,67)=0.39, p>0.05)$. Figure 2 shows the means for diastolic velocity averaged over both right and left anterior cerebral artery. The group main effect was significant for PI $(\mathrm{F}(2,69)=8.63, p<0.001)$ after controlling for diastolic blood pressure $(\mathrm{F}(1,67)=6.02, p<0.02)$. Age $(\mathrm{F}(1,67)=0.01, \quad p>0.05)$ and systolic blood pressure $(\mathrm{F}(1,67)=2.60, p>0.05)$ were not significant covariates in the latter analysis. Figure 3 shows means PI averaged over both right and left anterior cerebral artery. The mean PI for the Poly/NTS group was significantly larger than the CTL group $(p<0.04)$ and the Poly/Meth group $(p<0.01)$ using the Bonferroni multiple comparison post hoc procedure. There was no significant group by side interaction for any of the anterior cerebral artery measures.

\section{Effects of Current Drug Use in the Poly/Meth Group}

A total of 17 methadone-maintained subjects had a urine toxicology positive for heroin and/or cocaine at the time of the TCD testing and 11 subjects did not. To test whether the current drug use in the methadone-maintained subjects might have produced differences in the TCD measures, drug status (current use vs no current use) by side ANOVA was performed for all of the TCD measures. The means and results of these analyses are presented in Table 3. There were no differences between the methadone-maintained subjects who currently used drugs and those who did not on any of the blood flow velocity measures or PI.

\section{Controlling for Effects of Tobacco Smoking}

We attempted to eliminate the acute effects of nicotine on TCD measures by testing subjects $20 \mathrm{~min}$ or longer after cigarette smoking. Nevertheless, it was still possible that the effects of prolonged smoking might have confounded our pulsatility results. Thus, an analysis of covariance (group and side as factors) was performed on the PI values, with number of years of cigarette smoking used as the covariate to control for the prolonged effects of smoking. In the analysis for the PI from the MCA, the group main effect was significant for PI $(\mathrm{F}(2,71)=19.21, p<0.0001)$ whereas years of smoking $(\mathrm{F}(1,71)=0.014, p<0.50)$ was not a significant covariate. In the analysis for the PI from the ACA, the group main effect was significant for PI $(F(2,71)=13.50$,

Table 3 Effects of Current Drug Use on Cerebral Blood Flow Velocity Measures in Poly/Meth Group

\begin{tabular}{|c|c|c|c|c|c|c|}
\hline \multirow[b]{2}{*}{ TCD measure } & \multicolumn{2}{|c|}{$\begin{array}{l}\text { Nonusers } \\
(N=I I)\end{array}$} & \multicolumn{4}{|c|}{$\begin{array}{l}\text { Current users } \\
(N=17)\end{array}$} \\
\hline & $\operatorname{Mean}^{a}$ & SD & Mean & SD & $\mathbf{F}^{\mathbf{b}}$ & Probability \\
\hline$M C A V_{m}(\mathrm{~cm} / \mathrm{s})$ & 62.421 & 14.549 & 62.914 & 13.033 & 0.009 & 0.924 \\
\hline$M C A V_{s}(\mathrm{~cm} / \mathrm{s})$ & 97.378 & 22.411 & 97.995 & 20.411 & 0.006 & 0.940 \\
\hline$M C A V_{d}(\mathrm{~cm} / \mathrm{s})$ & 42.201 & 10.134 & 42.510 & 9.291 & 0.007 & 0.932 \\
\hline MCA PI & 0.883 & 0.101 & 0.882 & 0.123 & 0.001 & 0.986 \\
\hline ACA $V_{m}(\mathrm{~cm} / \mathrm{s})$ & 60.351 & 14.508 & 57.036 & 12.270 & 0.483 & 0.493 \\
\hline$A C A V_{s}(\mathrm{~cm} / \mathrm{s})$ & 90.136 & |7.39| & 85.282 & $20.37 \mid$ & 0.517 & 0.479 \\
\hline$A C A V_{d}(\mathrm{~cm} / \mathrm{s})$ & 40.977 & 8.969 & 37.693 & I I.083 & 0.797 & 0.380 \\
\hline ACA PI & 0.838 & 0.103 & 0.866 & 0.122 & 0.476 & 0.496 \\
\hline
\end{tabular}

aMean of the right and left artery over all subjects in this group. ${ }^{b} \mathrm{df}=1,26$. $p<0.0001)$ whereas years of smoking $(\mathrm{F}(1,71)=0.467$, $p<0.50$ ) was not a significant covariate.

\section{DISCUSSION}

Pulsatility index was increased in polysubstance abusers not seeking treatment compared to controls and methadonemaintained subjects. The mean PI values $(0.81+0.10)$ observed in 30 to 40 -year-old control subjects in the present study are comparable to those observed by other researchers (Martin et al, 1994; Steinmeier et al, 1993; Arjona and Prula, 2002). Specifically, mean normative or control values for PI values in the middle cerebral artery for persons under 40 years of age were reported to be 0.82 with $95 \%$ confidence interval from 0.78 to 0.87 (Martin et al, 1994), 0.84 with a standard deviation of 0.16 (Steinmeier $e t$ $a l, 1993$ ), and 0.76 with a standard deviation of 0.08 (Arjona and Prula, 2002). The methadone-maintained polysubstance abusers had elevated PI values, but these were lower than the nontreatment seeking polysubstance abusers (see Figure 3). Methadone treatment for 24 weeks, however, did not completely reverse these PI increases caused by abuse of multiple drugs.

The present observations using TCD sonography in this sample of polysubstance abusers are consistent with our previous reports (Herning et al, 1999, 2001, 2002; Jones et $a l, 2000)$ and support the suggestion that drug abuse is associated with abnormal cerebral hemodynamics. Studies of pulsatility indices in other patient populations suggest that increased cerebrovascular resistance is because of vasoconstriction of small cortical vessels (Martin et al, 1994, Biedert et al, 1995; Cho et al, 1997; Grubb et al, 1998). Patients with multi-infarct dementia have reported mean MCA PI values of $1.27+0.15$ (Biedert et al, 1995) and of 1.20 (standard deviation not given) (Sattel et al, 1996). Chronic hypertensives (Cho et al, 1997) and diabetic patients (Lee et $a l, 2000)$ have been reported to have PI increases, which correspond to means of 0.89 (standard deviation not given) and $0.87+0.22$, respectively. Middle cerebral artery PI values were found to be correlated with MRI measures of small vessel diseases characterized by periventricular hyperintensity (PI cutoff point for detection: 1.17), deep white matter hyperintensity (PI cutoff point for detection: 0.96), and lacunar disease (PI cutoff point for detection: 0.96) (Kidwell et al, 2001). When considered with these observations, our findings suggest that the repeated use of heroin and cocaine may contribute to a state of vascular insufficiency with a mean PI value of 0.98 that cannot be completely reversed by methadone. These observations also suggest that chronic abuse of these drugs might be associated with damage in the brain parenchyma.

This study also found that mean and systolic blood flow velocity in the middle cerebral artery was increased in methadone-maintained polysubstance abusers as compared with the control subjects after statistically correcting for a difference in age. While systolic blood pressure was also higher for the methadone-maintained subjects, systolic blood pressure was not related to the group differences as revealed by the analysis of covariance. This increase in blood flow velocity in the methadone-maintained polysubstance abusers relative to control subjects suggests a

Neuropsychopharmacology 
constriction in the middle cerebral artery as reported in other studies that have used patients with vascular disorders (Silvestrini et al, 1996; Howard et al, 1996). Since our observations of increased systolic velocity in the methadone patients are in contrast to those found in cocaine abusers (Herning et al, 1999), these changes might be secondary to the specific effects of methadone on the neural controls of the cerebral vasculature.

Since these polysubstance abusers used both cocaine and heroin, an important question that remains unanswered is whether the perfusion changes observed in the nontreatment seeking polysubstance abusers were due to the prolonged use of both substances or only to the prolonged use of cocaine. Previous studies found reduced perfusion in recently abstinent heroin abusers, findings possibly attributable to opiate withdrawal (Rose et al, 1996). The present study reported increased cerebral resistance in methadonemaintained polysubstance abusers and nontreatment seeking polysubstance abusers who recently used both cocaine and heroin. Several groups of investigators have reported reduced flow or metabolism in cocaine abusers (Tumeh et al, 1990; Weber et al, 1990; Volkow et al, 1991; Holman et al, 1991; Levin et al, 1994, 1995; Herning et al, 1999). Moreover, increased flow resistance, using TCD, has been found to persist even after a month of monitored abstinence (Herning et al, 1999). Thus, it is possible that the increased flow resistance observed in the polysubstance abusers in the present study might be due solely to the prolonged use of cocaine. This question could be resolved by evaluating cerebral perfusion in a sample of individuals who have a history of abusing only heroin and are currently abstinent from all opiates. Such patients are difficult to find, however.

It is important to note that methadone-maintained polysubstance abusers who were currently using cocaine and heroin had similar blood flow velocity values as those methadone-maintained polysubstance abusers who were not currently using these drugs. Thus, recent use of other drugs appears not to directly affect blood flow velocity measures in the methadone-maintained subjects since both groups of methadone-maintained subjects have blood flow velocity values with similar means and standard deviations. Thus, the improved measures in the methadone-maintained subjects might possibly be because of the prolonged effects of methadone.

It is also possible to suggest that these difference in flow resistance are attributable to cigarette smoking because smoking has been reported to cause acute changes in vascular flow (Cruickshank et al, 1989; Kodaira et al, 1993; Morioka et al, 1997). However, observations on the effects of cigarette smoking on the cerebral vasculature conflict with each other, with some investigators reporting increases (Kodaira et al, 1993) and others reporting decreases in cerebral blood flow lasting during smoking and $5 \mathrm{~min}$ after smoking (Cruickshank et al, 1989; Morioka et al, 1997). More importantly, however, our analysis of covariance revealed that the number of years that the subjects smoked did not influence the PI results. Furthermore, preliminary data from this laboratory have also documented that chronic cigarette smoking does not alter the pulsatility index (Herning et al, unpublished).

Since this was a cross-sectional study, our results might be secondary to other uncontrolled factors. In an attempt to rule out other possible confounds, all the volunteers underwent extensive medical, neurological, psychological, and laboratory evaluations. In addition, the methadonemaintained polysubstance abusers were tested after a uniform period of treatment $(24.3+3.3$ weeks $)$. Other factors related to social economic status could have also contributed to these abnormalities. However, all of the subjects came from similar income groups, with some control subjects actually making less money than the substance abusers. Nevertheless, it is still necessary to consider the possibility that these blood flow differences might be because of undetermined differences between drug abusers who seek and those who do not seek treatment.

In conclusion, this is, to our knowledge, the first study to evaluate cerebral blood flow by TCD in polysubstance abusers maintained on methadone for an extended period. Our findings suggest that the vasculature of 30 to 40 -yearold polysubstance abusers might be compromised, thus putting them at risk for cerebrovascular accidents (Strandgaard, 1993; Jamrozik et al, 2000), small vessel diseases (Lee et al, 2000; Kidwell et al, 2001), and/or cognitive impairments (Anstey and Smith, 1999; Rabbitt and Lowe, 2000). Our study reveals that treatment with methadone can reduce these abnormalities, although this therapeutic approach did not normalize these measures. Finally, our present observations further strengthen the view that heroin and cocaine abuse might result in parenchymal damage secondary in flow deficits to various brain regions of drug abusing subjects. Such damage might then be accompanied by various degrees of clinically significant neurobehavioral syndromes, the treatment of which will necessitate a more thorough neuropsychiatric approach that takes into account possible changes in cerebrovascular hemodynamics.

\section{REFERENCES}

Anstey KJ, Smith GA (1999). Interrelationships among biological markers of aging, health, activity, acculturation, and cognitive performance in late adulthood. Psychol Aging 14: 605-618.

Arjona A, Prula LA (2002). Mean velocity and pulsatility index in primary headaches. Rev Neurol 34: 414-316.

Arnolds BJ, von Reutern GM (1986). Transcranial Doppler sonography: examination technique and normal reference values. Ultrasound Med Biol 12: 115-123.

Ben Dians MK, Feroni I, Ponet M, Obadia Y (2000). Chief health risks associated with intravenous heroin and cocaine abuse. Presse Med 29: 453-457.

Biedert S, Hwer W, Forst H (1995). Multiinfarct dementia vs Alzheimer's disease: sonographic criteria. Angiology 46: 129135.

Cho S, Kim GW, Sohn YH (1997). Blood flow velocity changes in the middle cerebral artery as an index of chronicity of hypertension. J Neurol Sci 50: 77-80.

Community Epidemiology Work Group (2001). Epidemiologic trends in drug abuse. Proceedings of the Community Epidemiology Work Group; Bethesda. NIH publication No. 01-4916A.

Cruickshank JM, Neil-Dwyer G, Dorrance DE, Haynes Y, Patel S (1989). Acute effects of smoking on blood pressure and cerebral blood flow. J Hum Hypertens 3: 443-339.

Czosnyka M, Pickard J, Whitehouse HE, Richards HK (1996). Relationship between transcranial Doppler-determined pulsatility index and cerebrovascular resistance: an experimental study. J Neurosurg 84: 79-84. 
Danos P, Kasper S, Grunwald F, Klemm E, Krappel C, Broich K et al (1998). Pathological regional cerebral blow flow in opiatedependent patients during withdrawal: a HMPAO-SPECT study. Neuropsychobiology 37: 194-199.

Grubb BP, Hahn H, Elliott L, Brewster P, Wolfe D, Kosinski D et al (1998). Cerebral syncope: loss of conscious associated with cerebral vasoconstriction in the absence of systemic hypotension. Pacing Clin Electrophysiol 21: 652-658.

Herning RI, Better W, Tate KY, Cadet JL (2001). Marijuana abusers are at increased risk for stroke: preliminary evidence from cerebrovascular perfusion data. In: Slikker W, Trembly B (eds). Neuroprotective Agents: Fifth International Conference. Ann NY Acad Sci 939: 411-415.

Herning RI, King DE, Better WE, Cadet JL (1999). Neurovascular deficits in cocaine abusers. Neuropsychopharmacology 21: 110118.

Herning RI, Tate KY, Better W, Cadet JL (2002). Cerebral blood flow pulsatility deficits in HIV+cocaine abusers: differences associated with antiviral medications. Drug Alcohol Depend 65: 129-135.

Holman BL, Carvalho PA, Mendelson J, Teoh SK, Nardin R, Hallgring JK et al (1991). Brain perfusion is abnormal in cocaine-dependent polydrug users: a study using technetium99m-NMPAO and ASPECT. J Nucl Med 32: 1206-1210.

Howard G, Baker WH, Chambless LE, Howard VJ, Jones AM, Toole JT (1996). An approach for the use of Doppler ultrasound as a screening tool for hemodynamically significant stenosis. Stroke 27: 1951-1957.

Hser YI, Hoffman V, Grella CF, Anglin MD (2001). A 33-year follow-up of narcotic addicts. Arch Gen Psychiatry 58: 503-508.

Jamrozik K, Broadhurst RJ, Forbes S, Hankey GJ, Anderson CS (2000). Predictors of death and vascular events in the elderly: the Perth Community Stroke Study. Stroke 31: 863-868.

Johnson RE, Chutuape MA, Strain EC, Walsh SJ, Stitzer WL, Bigelow GE (2000). A comparison of levomethadyl acetate, buprenorphine, and methadone for opioid dependence. $N$ Engl J Med 343: 1290-1297.

Jones HE, Herning RI, Cadet JL, Griffiths RR (2000). Caffeine withdrawal increases blood flow velocity and alters quantitative electroencephalographic activity. Psychopharmacology 147: 371377.

Kidwell CS, El-Saden D, Livhits Z, Martin NA, Glenn TC, Saver JL (2001). Trancranial Doppler pulsatility indices as a measure of diffuse small-vessel disease. J Neuroimaging 11: 229-235.

Kodaira K, Fujishiro K, Wada T, Satoi T, Tsukiyana E, Fukumoto T et al (1993). A study on cerebral nicotine receptor distribution, blood flow, oxygen consumption and other metabolic activities- a study on the effects of smoking on carotid and cerebral artery blood flow. Yakubutsu Seishin Kodo 13: 157-165.

Lee KY, Sohn YH, Baik JS, Kim GW, Kim S-J (2000). Arterial pulsatility as an index of cerebral microangiopathy in diabetes. Stroke 31: 1111-1115.

Levin JM, Holman BL, Mendelson TH, Teoh SK, Garanda B, Johnson KA et al (1994). Gender differences in cerebral perfusion in cocaine abuse: technetium-99m-HMPAO SPECT study of drug using women. J Nucl Med 35: 1902-1909.

Levin JM, Mendelson JH, Holman BL, Teoh SK, Garada B, Schwartz RB et al (1995). Improved regional cerebral blood flow in chronic cocaine polydrug users treated with buprenorphine. J Nucl Med 35: 1902-1904.

Martin PJ, Evans DH, Naylor AR (1994). Transcranial color-coded sonography of basal cerebral circulation: reference data from 115 volunteers. Stroke 25: 390-396.

McLellan AT, Luborsky L, Cacciola J, Griffith J, McGaham P, O'Brien CP (1986). Guide to the Addiction Severity Index: Background, Administration, and Field Testing Results. National Institute on Drug Abuse, Treatment Research Reports: Rockville, MD.

Monitoring the Future Study, National Results on Adolescent Drug Abuse: Overview of Key Findings (2000). NIDA 3, 37pp, BKD361.

Morioka C, Konodo H, Akashi K, Matsumura K, Ochi N, Makinaga $\mathrm{G}$ et al (1997). The continuous and simultaneous blood flow velocity measurement of four cerebral vessels and a peripheral vessel during cigarette smoking. Psychopharmacology 131: 220229.

O'Connor PG, Fiellin DA (2000). Pharmacologic treatment of heroin-dependent patients. Ann Intern Med 133: 40-54.

Preston KL, Umbricht A, Epstein DH (2000). Methadone dose increase and abstinence reinforcement for treatment of continued heroin use during methadone maintenance. Arch Gen Psychiatry 57: 395-404.

Rabbitt P, Lowe C (2000). Patterns of cognitive ageing. Psychol Res 63: $308-316$.

Robins S, Helzer JE, Cuttler L, Golding E (1988). National Institute of Mental Health Diagnostic Interview Schedule Version III-R.

Rose JS, Branchey M, Buydens-Branchey L, Stapleton JM, Chasten $\mathrm{K}$, Werrell A et al (1996). Cerebral perfusion in early and late opiate withdrawal: a technetium-99m-HMPO SPECT study. Psychiatry Res: Neuroimaging 67: 39-47.

Sattel H, Biedert, Forstl H (1996). Senile dementia of Alzheimer type and multi-infarct dementia investigated by transcranial Doppler. Dementia 7: 41-46.

Silvestrini M, Troisi E, Matteis M, Cupini LM, Caltagirone C (1996). Transcranial Doppler assessment of cerebrovascular reactivity in symptomatic and asymptomatic severe carotid stenosis. Stroke 27: 1970-1973.

Strandgaard S (1993). The cerebral circulation in the elderly: the influence of age, vascular disease, and antihypertensive treatment. Am J Geriatr Cardiol 2: 32-36.

Steinmeier R, Laumer R, Bondar I, Priem R, Fahlbush R (1993). Cerebral hemodynamics in subarachnoid hemorrhage evaluated by transcranial Doppler sonography. Part 2. Pulsatility index: normal reference values and characteristics in subarachoid hemorrhage. Neurosurgery 31: 10-19.

Tumeh SS, Nagel JS, English RJ, Moore M, Holman BL (1990). Cerebral abnormalities in cocaine abusers: demonstration by SPECT perfusion brain scintigraphy. Radiology 176: 821-824.

van Dyck $\mathrm{CH}$, Rosen MI, Thomas M, McMahon TJ, Wallace EA, O'Connor PG et al (1994). SPECT regional cerebral blood flow alteration in naltrexone-precipital withdrawal from buprenorphine. Psychiatry Res: Neuroimaging 55: 181-191.

Volkow ND, Fowler JS, Wolf AP, Hitzemann R, Dewey S, Hoff A (1991). Changes in brain glucose metabolism in cocaine dependence and withdrawal. Am J Psychiatry 148: 621-626.

Weber DA, Klieger P, Volkow ND, Sacher D, Ivanovic M (1990). SPECT regional cerebral blood flow (rCBF) studies in crack users and control subjects. J Nucl Med 31: 876-877. 